\title{
Mobile Application for the Education of Diabetes Self-Management*
}

\author{
Dana Lateef Hussein \\ Computer Science Institute, \\ Sulaimani Polytechnic University, Sulaimani, Iraq \\ dana.hussen@spu.edu.iq
}

\author{
Hiwa Ali Faraj \\ College of Commerce, \\ University of Sulaimani, Sulaimani, Iraq \\ hiwa.faraj@univsul.edu.iq
}

\begin{abstract}
There has been, nowadays, a steady increase in using mobile phone by people worldwide. The mobile technology has an effective role on the civilization and very fast-rising in academic, health and industrial sectors. Mobile phones and internet-based technologies are used in the healthcare sector to strengthen communication between patients and healthcare sector such as Diabetes center. Additionally, the software that is used to for selfmanagement diabetes education, controlling and care of behavioral programs for Diabetes Mellitus. The only advanced solution for deficiency and disproportionate difficulties of old-style method is the implementation of a paper and pencil. This paper describes the development of a mobile health application based communication between the patients and the health center in order to deliver better health services. The main objective of this paper is providing $m$-health for treatment \& care selfmanagement diabetes in order enhance the quality of health services and reducing the cost.
\end{abstract}

Keywords: mobile technology, Diabetes, self-management diabetes education, Diabetes Mellitus.

\section{Introduction}

Complexity, cost and long term care are the most significant feature of the chronic disease for the patients' treatment, like diabetes and blood presser. The Mobile health (m-health) has been used as selfmanagement diabetes in order to enhance the quality of treatments and care for the patients.

Diabetes divides in to two main types Type 1 diabetes and Type 2 diabetes. The type 2 includes $\% 90$ of the patients. [13] It is a chronic illness in which the pancreas produces few or no insulin by itself. Diabetes is a chronic, metabolic disease characterized by elevated levels of blood glucose (or blood sugar), which leads over time to serious damage to the heart, blood vessels, eyes, kidneys, and nerves. [20][10]

Population is one of the main factors which led to the complexity in the society; the number of population is steadily increased through the world, especially in the developing countries. Chronic disease need long time care and treatments; it requires a lot of many and long term care by physician. The number of the physician in the most countries is out of the standard, privately in the developing countries. The life expenses are very expensive and human in the modern society have no a lot of free time. [12]

Health care expenditures to treat and prevent diabetes and its complications exceeded $\$ 465$ billion, indicating an opportunity and growing need to develop costeffective support tools and interventions for diabetes self-management, in the 2011 the number of diabetes patients are 366 Million. [2]

The number of patients' diabetes at 2013 has increased to 382 million people with diabetes. It is estimated the number of people with diabetes will increase by $55 \%$ by 2035 , (See figure 1). [19]

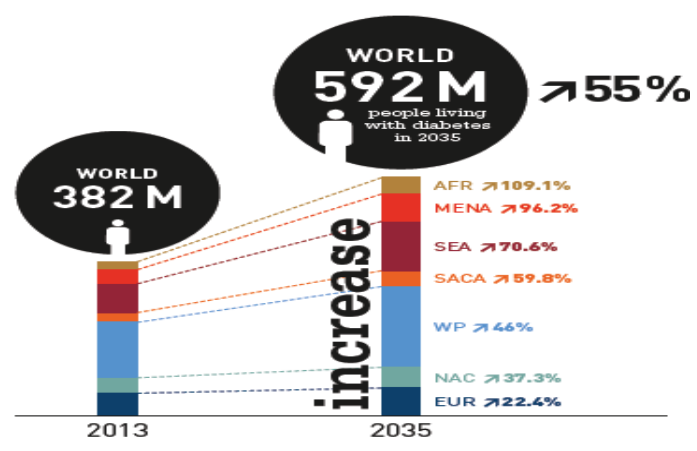

Figure 1 diabetes patients 2013-2035.

In the past three decades the prevalence of type 2 diabetes has raised dramatically in countries of all income levels. [20][10] In 2011, diabetes caused 4.6 million deaths [2] And by 2013 the diabetes death rate rich up to 5.1 million. [19] According to the diabetes center information the number of the diabetes patients in the Sulaimani-KRG-Iraq is 23000 who registered in the center, but there are a lot of patients have not registered and also they are many others have diabetes but they do not know about it. There are only two diabetes special physician in the center. Every 7 seconds one dies from diabetes, in 20144.9 million deaths. [19] There are $9 \%$ of adults in the world have diabetes. Type 1 and type 2 are suffering and enormous costs, so Self-management is critical to reaching better

*This paper was presented at the Third International Scientific Conference of University of Human Development (April, 2016) 
management are significant in reducing long-term diabetes complications.[13] Culture \& lifestyle factors are playing a great role for $\mathrm{m}$-health self-management reduction of long-term diabetes. 14] Today the current generation of mobile device became so ubiquitous in our culture. The role of the mobile has extends the classical communication function. The new mobile has a lot of functionality such as, economic, Health, entertainments and also social communication.

International Telecommunication Union estimated by the end of 2015 the mobile-cellular telephone subscription per 100 inhabitants will go up to $\% 96.8$ and the individuals using the internet will reach 43.3, see figure 2. [22] According to this data the mobile user availability will assist the DSM m-health.

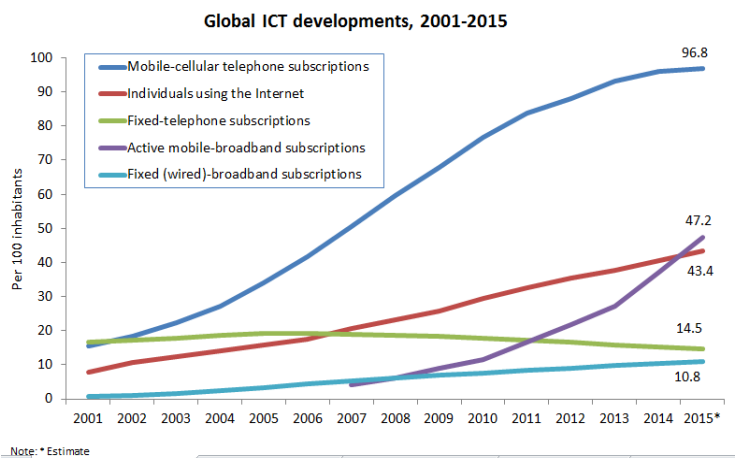

Figure 2 shows mobile \& individual internet user.

In this paper the mobile device has been used to overcome the barriers in the health sectors. Mobile use as the same meaning with Smartphones, PDAs and other similar devices present the user with a variety of ways to communicate with the touch of a finger. The main objective of this paper is providing m-health for treatment \& care self-management diabetes in order enhance the quality of health services and reducing the cost.

The term mobile health (m-Health), describes the use of mobile telecommunication and multimedia technologies as they are integrated within increasingly mobile and wireless health care delivery systems. [21] This paper describes the program involves the $\mathrm{m}$ health. The key component is the mobile m-health diabetes that is updated both by manual user input and automatically by wireless data transfer using medical sensors and receive the physician's feedback. It also includes the tutorial overview and guidelines about the diabetes.

\section{Total Expenditure on Health and Average of Life Expectancy at Birth}

There are four parameter in the tables, (see Table 1), Countries, population, total expenditure on health as \% of GDP and average of life expectancy at birth of 16 countries out of 81 countries. [21] R-squared has used to find the relationship between the parameters. Rsquared result shown in the (Table 2), according to the analysis of R-square equal to one that means there are strong relationship between Average of life expectancy at birth and Total expenditure on health as \% of GDP. In addition there are positive relationships the both parameter, as much as total expenditure on health as \% of GDP increase the Average of life expectancy at birth also increase, vice versa.

Table 1 The countries information [25] [26].

\begin{tabular}{|c|c|c|c|c|}
\hline Code & Countries & $\begin{array}{c}\text { Total } \\
\text { expenditure } \\
\text { on health as } \\
\% \text { of GDP } \\
\text { (2013) }\end{array}$ & $\begin{array}{c}\text { Total } \\
\text { population } \\
(2013)\end{array}$ & $\begin{array}{l}\text { Average Of } \\
\text { Life } \\
\text { expectancy } \\
\text { at birth } \mathrm{m} / \mathrm{f} \\
\text { (years, } \\
\text { 2013) }\end{array}$ \\
\hline 1 & Algeria & 6.6 & 39208000 & 72 \\
\hline 2 & Albania & 5.9 & 3173000 & 74.5 \\
\hline 3 & Andorra & 8.1 & 79000 & 82.5 \\
\hline 4 & Angola & 3.8 & 21472000 & 51.5 \\
\hline 5 & Argentina & 7.3 & 41446000 & 76.5 \\
\hline 6 & Armenia & 4.5 & 2977000 & 71 \\
\hline 7 & Australia & 9.4 & 23343000 & 82.5 \\
\hline 8 & Austria & 11 & 8495000 & 81.5 \\
\hline 9 & Azerbaijan & 5.6 & 9413000 & 72.5 \\
\hline 10 & Bahrain & 4.9 & 1332000 & 77 \\
\hline 11 & Belgium & 11.2 & 11104000 & 80.5 \\
\hline 12 & Brazil & 9.7 & 200362000 & 75.5 \\
\hline 13 & Bulgaria & 7.6 & 7223000 & 74.5 \\
\hline 14 & Cameroon & 5.1 & 22254000 & 57 \\
\hline 15 & Canada & 10.9 & 35182000 & 82 \\
\hline 16 & Chile & 7.7 & 17620000 & 80 \\
\hline
\end{tabular}

Table 2 The R-Squared analysis

\begin{tabular}{|l|r|}
\hline \multicolumn{2}{|c|}{ SUMMARY OUTPUT } \\
\hline \multicolumn{2}{|c|}{ Regression Statistics } \\
\hline R Square & 1 \\
\hline Adjusted R Square & 1 \\
\hline Standard Error & $\mathbf{0 . 0 0 0 0 0 0 0 0 0 0 0 0 0 0 5 8}$ \\
\hline Observations & $\mathbf{8 1}$ \\
\hline
\end{tabular}

In the Iraq and many of the developing countries the total expenditure on health is less than 5.5 and the average of life expectancy at birth is less than the 
countries which total expenditure on health are greater than 8 . So the m-health has been suggested as a key component for the diabetes self- management in order to deliver better quality of health services and reducing the costs.

\section{Diabetes Self-Management Education Using Mobile}

Diabetes Self-Management education (DSME) is a method for dealing with diabetes care. The methods should be up-to-date, it include group activity in purpose of changing the lifestyle of the patients, such as; practical information on nutrition, exercise, new drugs, medical, self-help.[10] DSME is an educational program that aims to improve self-management behavior to reduce risks associated with diabetes. [1] Diabetes self-management education (DSME) is a critical element of care for all people with diabetes and those at risk for developing the disease. It is necessary in order to prevent or delay the complications of diabetes and has elements related to lifestyle changes that are also essential for individuals with pre diabetes as part of efforts to prevent the disease. [9][10]

There are a lot of programs for Diabetes SelfManagement Education (DSME), such as:

- American Diabetes Association (ADA) Recognized Education Programs.

- American Association of Diabetes Educators (AADE) Diabetes Education Accredited Programs. [22]

ADA position statement that is provides evidencebased clinical practice recommendations for diabetes care. Whereas the "Standards of Medical Care in Diabetesd2015", it has been divided into 14 sections, each individually referenced, to highlight important topic areas and to facilitate navigation. The supplement now includes an index to help readers find information on particular topics. [10] [23]

The standards are reviewed and revised every 5 years key stakeholders and experts, because of the dynamic nature of health care and diabetes-related research. The National Standards designed to define quality Diabetes self-management education and support and to assist diabetes educators in providing evidence-based education and self-management support. [12]

The American Association of Diabetes Educators (AADE) has defined the AADE7 Self-Care Behavior as a framework for patient centered diabetes selfmanagement education (DSME) and care. [23] The seven self-care behaviors essential for successful and effective diabetes self-management are:

- Healthy Eating

- Being Active

- Monitoring

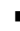

Taking Medications

- $\quad$ Problem Solving

- Healthy Coping

- $\quad$ Reducing risks. [23]

The training includes (DSME involves classroom training on healthy choices, taking medications, monitoring blood glucose levels, and other aspects of living with diabetes. Patients participate in demonstration, observation, role playing and problem solving scenarios to acquire skills in DSME. [12] According to the programs the patients educate with the groups of activity and knowledge. Mobile can be used for a lot of activities such as, diabetes overview; managing contact with the diabetes center and receiving the feedbacks, also mobile will help the disabilities diabetes patients much better. Mobile will not be the alternative for the classroom training, it just uses for managing the education and contact with centre, in order to reduce the cost and simplified the process.

Mobile health covers "medical and public health practice supported by mobile devices, such as mobile phones, patient monitoring devices, personal digital assistants (PDAs), and other wireless devices. [6] Through sensors and mobile apps, m-Health allows the collection of considerable medical, physiological, lifestyle, daily activity and environmental data. This could serve as a basis for evidence-driven care practice and research activities, while facilitating patients' access to their health information anywhere and at any time. [17]

Information at the point of care: Mobile health solutions allow medical professionals to provide medical care and services regardless of whether the patient is in hospital, at home or elsewhere in the community. The Mobile devices can assist health professionals in their day to day routine by facilitating the provision of timely information required for providing safe care. [14] They can also be used in medical research, used for clinical trials to record and transmit data that are costly to capture by traditional methods. In the m-Health Server, the Electronic Health Records (EHR), are present at the Hospital end for further analysis presented via Web Site, which the physician can access [3][11].

\section{Literature Review}

The major goal of electronic health programs is to use Information and Communication Technology (ICT) to make better healthcare service process and health outcomes due to the use of IT for example computers, internet, satellite, mobile phones, and Personal Digital Assistants (PDA). 
Mobile phone application uses as a modern tool for delivery health services. Mobile Health technologies are divided into the following categories: mobile phones, smart phones, mobile tele-health devices, MP3/MP4 players, and mobile computing. [4]

The mobile applications have been used for delivering health services in the various fields, especially for the long term diseases such as diabetes. There are a lot of types of mobile health for instance; awareness and education, remote monitoring, manage appointments diagnostic and treatment.

The take advantage of Information and Communication Technology in the field of health has become an adequate in the low and average countries. This method has been set up to overwhelmed widespread health system obstacles such as health specialized limitation, dependence on inexpert and/or informal providers, cost of service and transportation, and shortage of sources of authoritative information. [18]

Ivatury, Moore and Bloch reported that the use of call center, Hotline, have been using in Canada, the United Kingdom, and United States of America, for decades, while in the developing countries such as Bangladesh, India, Mexico, and Pakistan has recently started [18]. The limitations of this project include the absence of affordability of services for the poorest sections of the population, unavailability in the area because of the limited coverage of the network connection and female a few frequent has or have access to mobile phone and non-incorporation of health call center systems with other resources of data [18].

According to the Vital Wave Consulting, The main electronic mobile health in developing countries divided to six categories for example education and awareness, remote data collection, remote monitoring, communication and training for healthcare workers, disease and epidemic outbreak tracking and diagnostic and treatment support. [16]

Caroline Marshall, Don Lewis and Maxine Whittaker documented the minimal account of the diabetes health delivery (Vital Wave Consulting 2009a) whereas World Health Organization (WHO) divide m health for diabetes in to large number of types groups, see table 3 . [5]

According to Ian L. FRENG $\mathrm{m}$ health for diabetes health services delivery divided into five categories such as; mobile-enhanced appointment booking systems, drug authentication and tracking, well-being applications, and remote diagnosis. [8]

According to the research by the United Nations Foundation and Vodafone Foundation has counted more 51 categories of application, the applications are emphasis on six main fields. The applications are using in the 26 nations through the world. The area of the application are treatment and support services, health education and awareness services, data collection and remote monitoring services, disease surveillance and drug adherence services, health information systems and point of care services, and emergency medical services. [4] [24]

Table 3 Diabetes types groups

\begin{tabular}{|c|c|}
\hline $\begin{array}{l}\text { Category - Vital Wave Consulting } \\
\text { (2009a) }\end{array}$ & Category - World Health Organization (2011b) \\
\hline Education and awareness & $\begin{array}{l}\text { - } \text { Raising awareness } \\
\text { - } \text { Health call centres } \\
\text { - Emergency toll-free telephone lines } \\
\text { - } \quad \text { Community mobilization and health } \\
\text { promotion } \\
\text { - Information initiatives }\end{array}$ \\
\hline Remote data collection & $\begin{array}{l}\text { - Health surveys and surveillance } \\
\text { - Patient records }\end{array}$ \\
\hline Remote monitoring & $\begin{array}{ll}\text { - } & \text { Appointment reminders } \\
\text { - } & \text { Treatment compliance } \\
\text { - } & \text { Patient monitoring }\end{array}$ \\
\hline $\begin{array}{l}\text { Communication and training for health } \\
\text { care workers }\end{array}$ & - Mobile telemedicine \\
\hline $\begin{array}{l}\text { Disease and epidemic outbreak } \\
\text { tracking }\end{array}$ & $\begin{array}{l}\text { - Public health emergencies } \\
\text { - Health surveys and surveillance }\end{array}$ \\
\hline Diagnostics and treatment support & $\begin{array}{l}\text { - Decision support system Telemedicine } \\
\text { - Patient records }\end{array}$ \\
\hline
\end{tabular}

Developing countries are facing problem to supply enough healthcare to the individual, privately in the rural areas. Educating and changing the behavior of the patients enhance the quality of care. Due to the mobile application the delivering the health care will be better, patients educate about the general information about the disease, types of the disease, the factors and treatments. Moreover the patients register their daily records; also it contains historical record about the patients' record. [4]

\section{Benefits of DSME m-Health}

The potential benefits of an effective patient education program Improving knowledge, lifestyle changes health beliefs, and reduce cost. The benefits of DSME divide in to direct and indirect benefits. Direct benefit relates with improving current patients statutes. Indirect benefits avoid number of serious complications that can significantly increase the financial impact of the disease [24]. Direct benefits of diabetes self-management education include the follows:

- Reductions in hospitalizations and improved blood-glucose control. 
- Participation of individuals with diabetes in DSME Programs leads to improved clinical outcomes, reduced diabetes-related complications, increased quality of life and reduced health care costs.

- Individualized assessment Individualized education Opportunity for family involvement Reduced risk of complications reduced medical care costs.[15]

- DSME m-heath helps the disabilities patients to obtain the knowledge and care at home.

Improper care and treatment with the diabetes patients increase serious kidney, cardiovascular events, such as heart attack, stroke, and death related to cardiovascular disease. Diabetes is associated with a number of serious complications that can significantly increase the financial impact of the disease. In particular, the micro vascular damage associated with diabetes can result in kidney failure, blindness, and lower-limb amputations. [4] Without proper care, the costs related to these complications can be extraordinarily high. Without proper care, the costs related to these complications can be extraordinarily high. For example, in 2011, total see figure 2, Medicare costs for kidney treatments such as hemodialysis, peritoneal dialysis, and transplants reached $\$ 24.3$ billion, $\$ 1.5$ billion, and $\$ 2.9$ billion, respectively. 19 Similarly see figure 2 as of 2001, diabetes-related amputations were estimated to cost $\$ 38,077$ per amputation while costs for foot ulcer care have been estimated at $\$ 13,179$ per episode. [4]

\section{Barriers to Self-Management of DSME M-Health}

The DSME M-health process is not simple, it require basic knowledge, education, language, changing lifestyle, the barriers such as health information. Patients found quite confusing about health information received on DM. The patients as the attending physicians are not forthcoming with information pertaining to diabetes and lack of awareness of target blood glucose level and of blood pressure as major barriers for improved selfmanagement of DM. Behavioral, Motivation and other psychological factors

A study identified motivation as a major barrier for self-management of DM [7]. Motivation may be extrinsic, such as the type of motivation provided by the health care team. Depression may negatively affect how individuals take care of themselves as such loss of interest, reduce decision making ability and fatigues are likely to contribute to the poor self-management of DSME. [7]

Program may not be conducive to those requiring low literacy or specific cultural focus, difficult to understand the language used in program, too much information and lack of individual (empowerment) approach. Knowledge of diabetes care has been associated with activities such as taking medication, diet, exercise; blood glucose monitoring and foot care. [18] [24]

\section{Design and Implementation of System for M-Health Application}

Delivering the long term disease cost a lot of money; so mobile health application has been used for selfmanagement diabetes (see figure 3 ) order to reduce the cost and delivery better health services. Due to the use of the mobile application the patients educate about their diseases and record their data in the mobile application, the record will helps the physician for better understanding about the diseases.

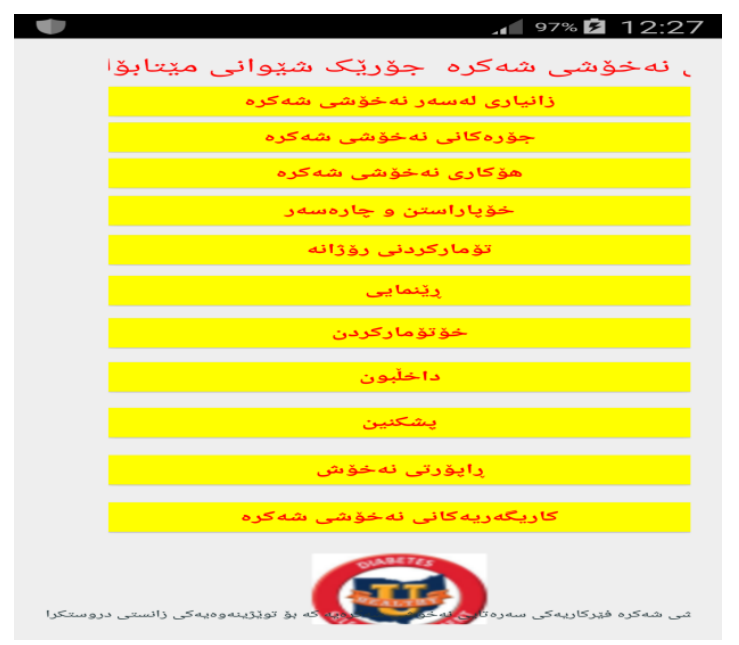

Figure 3 The main menu of the application.

The Apps for DSM education program which includes,

- General overview of diabetes, (see figure 4).

- Tacking medication (see figure 5)

- Basic nutrition, healthy eating (see figure 5)

- The importance of exercise (see figure6)

- Self - monitoring, (see figure 7).

The apps also includes diabetes related health problems such as,

- Heart Disease

- Stroke

- Vision loss (see figure 8).

Database is used to collect and manage the data, the system contains SQLite database which is android native, the patients save their daily record reports, (see figure 9). 

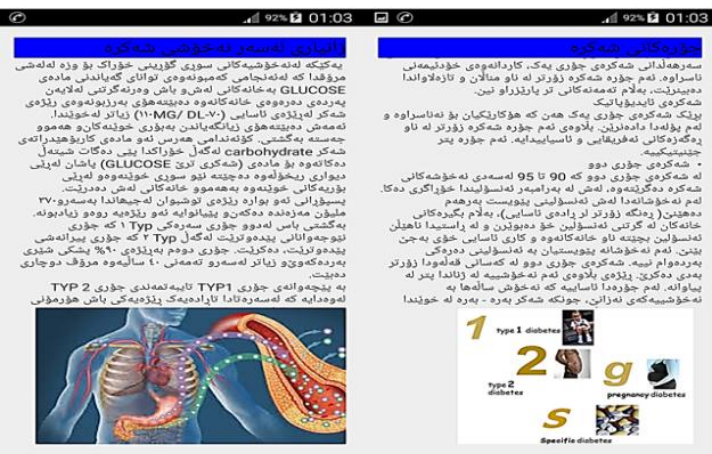

Figure 4 The General overview of diabetes.

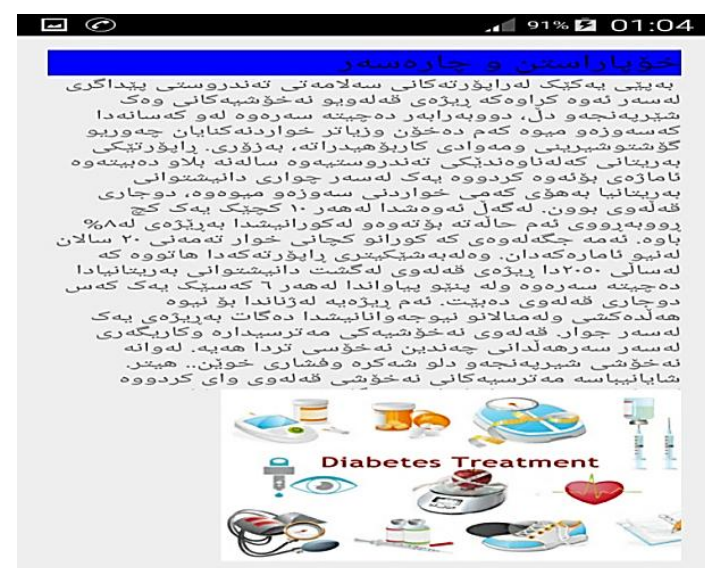

Figure 5 The Basic nutrition

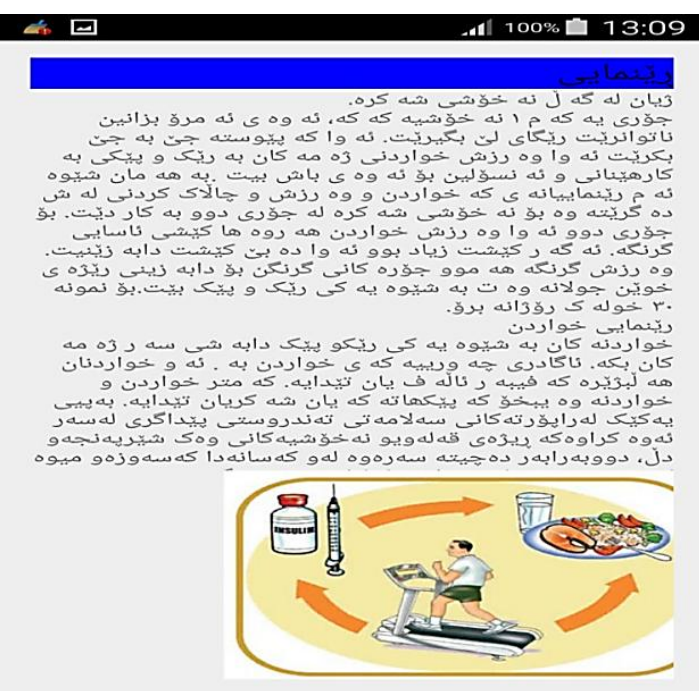

Figure 6 The importance of exercise
$\square(C)$ 91\% 01:05

$$
\begin{aligned}
& \text { توّماركردني روَزانه }
\end{aligned}
$$

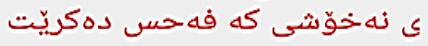

B1.P $\mathrm{mmHg}$

P.R.(beat/min)

Weight

Hight

BMI

Fasting/Random

B1.Suger(mg/dl)

HbA1c(\%)

$\mathrm{HbA1c}(\%)$

S.creatinine $(\mathrm{mg} / \mathrm{dl})$

S.cholestrol(mg/dl)

S.trigyceride(mg/dl)

S.HDL $(\mathrm{mg} / \mathrm{dl})$

Figure 7 Shows the Self-monitoring

\section{0 (6)}

.11 69\% 18:16

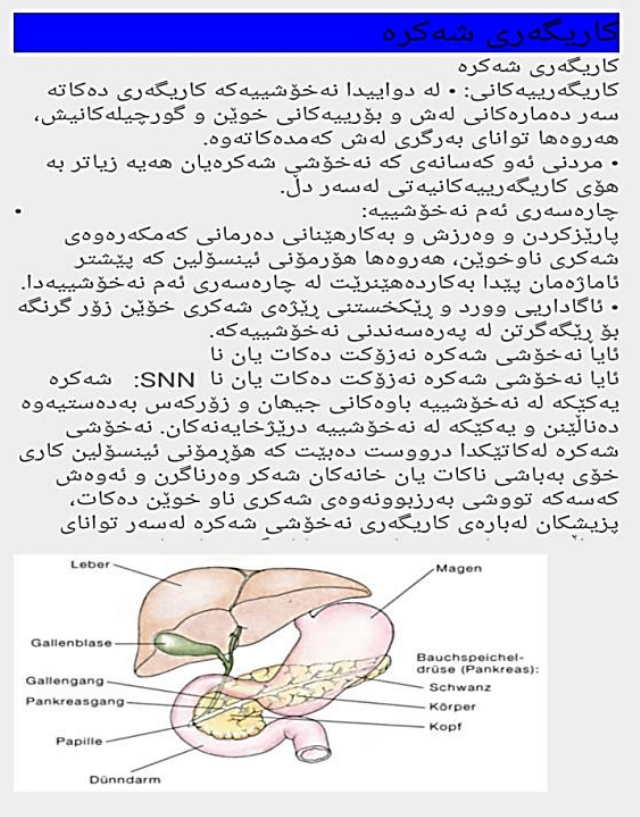

Figure 8 shows the Vision loss 


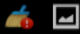
100\% 13:21

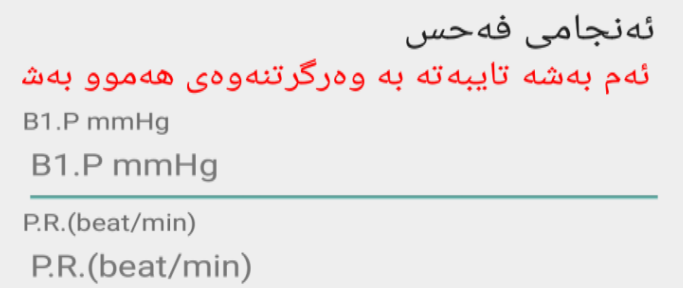

\begin{tabular}{l} 
Weight(kg) \\
Weight \\
\hline Hight(cm) \\
Hight
\end{tabular}

BMI(Body Mass Index)

BMI

Fasting/Random

Fasting/Random

B1.Suger(mg/dl)

B1.Suger(mg/dl)

HbA1c(\%)

$\mathrm{HbA1c}(\%)$

HbA1c(\%)

HhA1c. $\%)$

Figure 9 shows the daily record reports

\section{Conclusion and Future Work}

Mobile technology has a great role in humans being's life, it uses in many fields. In the last decade the smartphone became more popular and it has developed rapidly, mobile can be used for delivering a lot of services for example text messaging, video and audio streaming and remote connections. Currently there are trends toward self-treatment for the diabetes in order to enhance better services. There are a lot of application support mobile health services in the wide variety of ways such as; remote monitoring, education, diagnostic and treatment support. In this paper M-health has been used for diabetes self-treatment education has been covered. (See Figure 10) Education and training of the patients become a frontline which enhance the quality of health services and reduce the cost. M-health application for education the diabetes self-treatment could deliver better services and care with lees cost and it can be used as a solution for diabetes long term care.

The self-mobile education can be expanding which covers large area and functionality of the diabetes patients (See Figure 11). Causes of the diabetes coves overall picture of the system architecture of our proposed mobile health self-managements care system for patients with diabetes.

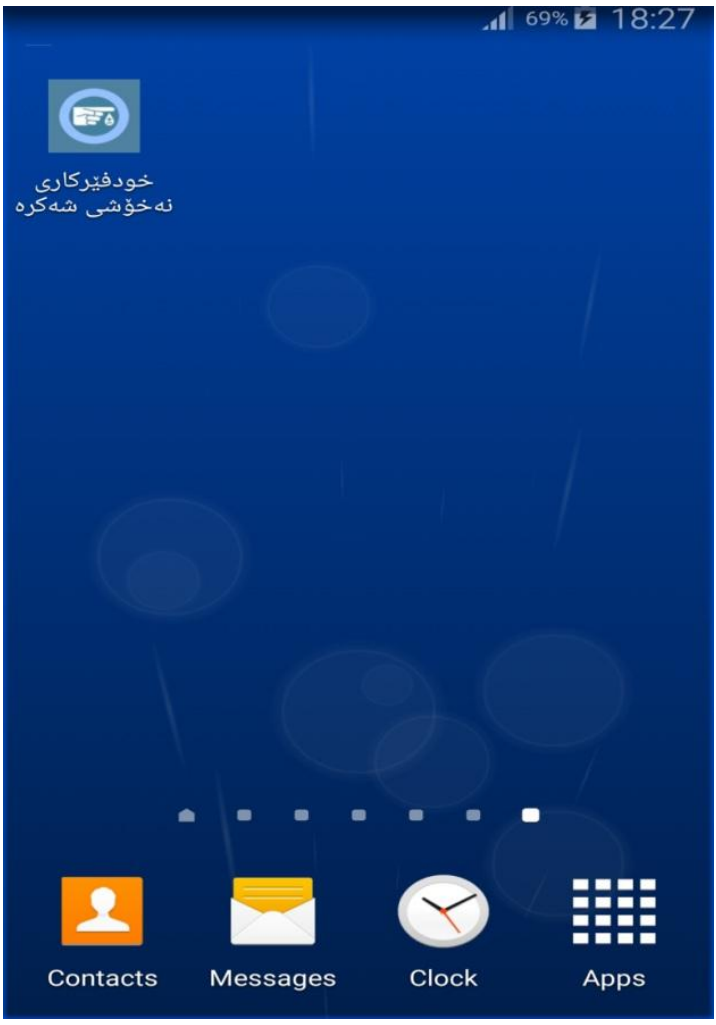

Figure 10 Diabetes self-treatment education program on the mobile phone

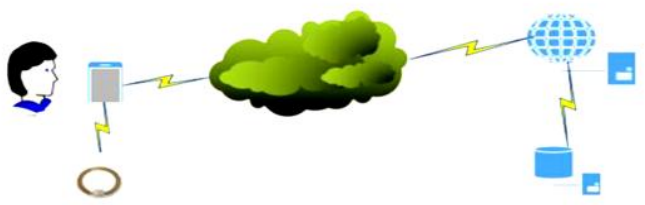

Figure 11 Implementation of the m-Health application

\section{References:}

1. American Diabetes Association, 2015. Standards of Medical Care in Diabetes: Summary of Revisions. Diabetes Care, 38(1), p (S4).

2. Årsand, E, Frøisland, D and Skrøvseth S, 2012. Mobile Health Applications to Assist Patients with Diabetes: Lessons Learned and Design Implications. Diabetes Science and Technology, 6(5): 11971206.

3. Arvind Rehalia, A and Chawla S, 2011. Role of Electronic Health Record in MHealth, International Journal of Biomedical Signal Processing, 2(2), pp. 93-94.

4. Arwa F. Albabtain, Dina A. AlMulhim, Faisel Y., Mowafa S. Househ, 2014. The Role of Mobile Health in the Developing World: A Review of Current Knowledge and Future Trends

5. Caroline Marshall, Don Lewis, Maxine Whittaker, 2013. mHealth technologies in developing countries: a feasibility assessment and a proposed framework

6. European Commission, 2014.Green Paper on mobile Health (mHealth). Brussels. 
7. G. Kisokanth, S. Prathapan, J, Indrakumar3 and J, Joseph, 2013. Factors influencing self-management of Diabetes Mellitus;

8. Ian L. FRENG, Simon S., Danny D., Nick G., Tao-Tao C., 2011. Mobile Communications for Medical Care

9. Linda Haas, Melinda Maryniuk, Joni Beck, Pharmd, Carla E, Paulina Duker, Laura Edwards, Edwin B. Lenita Hanson, 2012. National Standards for Diabetes Self-Management Education and Support;

10. Maine Department of Health and Human Services, 2006. Diabetes Self-Management Education Barrier Study.

11. Mirela Prgomet, BAppSc (Hons), Andrew Georgiou, $\mathrm{PhD}$, and Johanna I. Westbrook, PhD, 2009. The Impact of Mobile Handheld Technology on Hospital Physicians' Work Practices and Patient Care: A Systematic Review.

12. Pew Research Center, APRIL 2, 2015, "The Future of World Religions: Population Growth Projections, 2010-2050." http: //www.pewforum.org/2015/04/02/main-factors-driving-populationgrowth/. [Accessed date 22 July 2015].

13. S.Z. Inamdar, R.V. Kulkarni, 2016. "Impact of Pharmaceutical Care in the Management of Drug Related Problems and Complications in the Treatment of Type II Diabetes Mellitus: A Review"

14. Sezgin, E, Yıldırım, S, 2014. A Literature Review on Attitudes of Health Professionals towards

15. The center for health law and policy innovation of Harvard law school, "reconsidering cost-sharing for diabetes self-management education: recommendation for policy reform", 2015, (https://www.diabeteseducator.org/docs/defaultsource/advocacy/reconsidering-cost-sharing-for-dsme-chlpi-paths-611-2015-(final-draf.pdf?sfvrsn=2), [Accessed date 8 September 2015].

16. Vital Wave Consulting. M Health for Development: The Opportunity of Mobile Technology for Healthcare in the Developing World. Washington, D.C. and Berkshire, UK: UN FoundationVodafone Foundation Partnership, 2009.

17. William T Riley, PhD, Daniel E Rivera, PhD, Audie A Atienza, $\mathrm{PhD}$, Wendy Nilsen, PhD, Susannah M Allison, PhD, Robin
Mermelstein, PhD,2011. Health behavior models in the age of mobile interventions: are our theories up to the task.

18. World Health Organization, 2011. M Health: New horizons for health through mobile technologies: second global survey on eHealth.

\section{Webography References:}

19. International Diabetes Federation, 2013. IDF DIABETES ATLAS, International Diabetes Federation, (http://www.ncbi.nlm.nih.gov/pmc/articles/PMC3570855/EN_6E_At las_Ful_0.pdf) [Accessed date 8 September 2015].

20. WHO, $2014 . \quad$ Diabetes, http://www.who.int/diabetes/en/)[Accessed date 6 September 2015].

21. World Health Organization, 2007, Towards the Development of A mHealth Strategy: A Literature Review, (http://www.who.int/goe/mobile_health/mHealthReview_Aug09.pdf) [Accessed date 8 September 2015].

22. International Telecommunication Union, 2014. Statistics, (http://www.itu.int/ict/statistics) [Accessed date 15 October 2015]

23. Funseth Mary, Diabetes Self-Management Education, 2014. (http://www.metastar.com/providers/clinics-and-physicianoffices/the-atrium/diabetes-self-management-education/), [Accessed date 12 October 2015].

24. American Association of Diabetes Educators, 2014. "AADE7TM Self-Care Behaviors.

(https://www.diabeteseducator.org/docs/default-source/legacy-

docs/_resources/pdf/publications/aade7_position_statement_final.pdf ?sfvrsn=4), [Accessed date 8 August 2015].

25. Hendrick Diabetes Center, 2015. Diabetes Self-Management Education,

(http://www.hendrickhealth.org/Diabetes/DiabetesServicesandProgra ms.aspx) [Accessed date 8 August 2015].

26. WHO, Statistics, Countries Total population, 2014 "http://www.who.int/countries/en//. [Accessed date 22 July 2015]. 